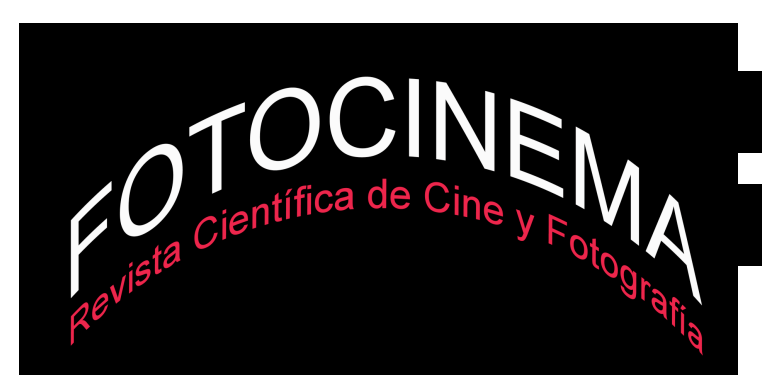

REVISTA CIENTÍFICA DE CINE Y FOTOGRAFÍA

E-ISSN 2172-0150 No 15 (2017)

Recibido 03-04-2017 / Aceptado 13-06-2017

Publicado 22/07/2017

\title{
BIGAS EN LA BOCA, LUNA ENTRE LAS PIERNAS. CINE, SEXO Y GASTRONOMÍA
}

\section{BIGAS IN THE MOUTH, LUNA BETWEEN THE LEGS. CINEMA, SEX AND GASTRONOMY}

\author{
Gonzalo M. Pavés \\ Universidad de La Laguna, España \\ gpavores@ull.es
}

\section{Resumen:}

Existen en el universo cinematográfico de Bigas Luna varios temas recurrentes que se pueden rastrear a lo largo de toda su filmografía. Uno de ellos, quizás el más evidente y persistente, es el del erotismo y su singular maridaje con la gastronomía. Desde luego no ha sido el único cineasta que ha plasmado en el celuloide esta deliciosa combinación, pero sí que la convirtió en una de las constantes más repetidas y lúcidas de toda su obra. Este artículo busca sintetizar qué pensaba el cineasta sobre la relación del sexo, los alimentos y el cine, un pensamiento que fue depurando y transformando a lo largo del tiempo, y en segundo lugar, ver como este pensamiento se concretó en una serie de evocadoras metáforas, de corte surrealista, que salpicaron casi todas sus películas.

\begin{abstract}
:
There exist in the cinematographic universe of Bigas Luna several recurring themes that can be traced throughout his filmography. One of them, perhaps the most evident and persistent, is that of eroticism and its unique pairing with gastronomy. Of course he has not been the only filmmaker who has captured this delicious combination in the celluloid, but he has turned it into one of the most repeated and lucid constants of all his work. This article seeks to synthesize what the filmmaker thought about the relationship of sex, food and cinema, a thought that was polished and transformed over time, and secondly, to see how this thought came to fruition in a series of evocative metaphors, of surrealist influence, that they splashed almost all his films.
\end{abstract}

Palabras claves: Bigas Luna; cine español; erotismo; gastronomía; sexualidad.

Key Words: Bigas Luna; Spanish cinema; eroticism; gastronomy; sexualit. 
Cómo citar: Pavés, G. M. (2017). "Bigas en la boca, Luna entre las piernas. Cine, sexo y gastronomía”. Fotocinema. Revista científica de cine y fotografía, $\mathrm{n}^{0}$ 15, pp. 13-35. ${ }^{1}$ Disponible: http://www.revistafotocinema.com/

El amor y la belleza pueden ser comidos

Bigas Luna

Su fama de erotómano persiguió a Bigas Luna durante toda su vida. Algunos lo calificaron de "pornócrata" cuando, con Bilbao (1978) y Caniche (1979), el cineasta catalán escandalizó al público de un país que trataba de zafarse de las mojigatas barreras levantadas por una larga dictadura. Aquellas primeras imágenes, ásperas y correosas, mostraban una sexualidad transgresora, a ratos oscuras, a ratos grotesca, que no daban una visión gratificante del sexo. Bigas emergía así, en plena Transición, como un realizador insólito dotado con un desafiante y sofisticado sentido de la imagen fruto de sus experiencias previas como diseñador, fotógrafo y artista plástico. Su tratamiento del sexo en sus primeras obras era distanciado, racional y, a veces, desconcertantemente gélido. Más tarde suavizó sus formas, entendió el sexo como algo vital, consustancial en la experiencia humana y medular en su obra creativa. De ese modo, toda su filmografía se apartó de ese otro cine español que, incapaz de enfrentarse a la sexualidad con naturalidad, optó por ignorarla, cultivarla "de manera elíptica, pacata, simbólica", o negarla reduciéndola "histéricamente a lo grosero" (Weinrichter, 1992, p. 12).

\section{En el banquete con Eros. Sexo y Gastronomía}

En el cine de Bigas el espectador no puede perder detalle. Su torrencial imaginación se desparrama, a través de sutiles guiños, metáforas, alusiones e

\footnotetext{
${ }^{1}$ El presente trabajo forma parte del proyecto de investigación $\mathrm{I}+\mathrm{D}+\mathrm{i}$ "Sociedad, democracia y cultura en el cine español de la era socialista (1982-1996)" HAR2015-66457-P financiado por el Ministerio de Economía, Industria y Competitividad.
} 
ironías, por un universo creativo autorreferencial y siempre en constante expansión. De todas sus preocupaciones, intereses y obsesiones que, como en juego de espejos enfrentados se repiten de una pintura a otra, de una película a la siguiente, el cineasta destacaba una tríada que consideraba esencial para comprender su vida y su obra: "Hay tres cosas que me interesan mucho. Y mi vida gira en torno a estas tres cosas", enumeraba divertido el cineasta, "Una es el erotismo, la comida, con el gusto, y la espiritualidad. Estas tres cosas son el triángulo obsesivo de mi vida" ${ }^{2}$. Efectivamente, uno de los rasgos más representativos de su filmografía es la presencia constante de la cocina, de la comida, en todas sus "variantes y características, desde los electrodomésticos (la batidora, la olla exprés, los vasos o los sartenes ) a los platos (el ajo, la cebolla, la paella o la tortilla de patata), desde lo permitido (el jamón, si se es cristiano viejo) a lo prohibido (la carne de perro, si no se es chino), desde lo tradicional (el aceite, si se pertenece a la cultura mediterránea) a los productos colonizadores (las palomitas), desde lo externo (ir de tapas) a lo escondido (pajaritos fritos)" (Sánchez, 1999, p.77). Pero este deleite cinematográfico por lo gastronómico no es ni superfluo, ni gratuito, su peculiaridad consiste en el singular maridaje propuesto por el cineasta entre sexo y alimentación.

Siempre digo que sería maravilloso que se unieran aún más, que después de la comida las señoras se sacaran una teta y nos la dejaran probar -como una cosa normal- después del café... Ese sabor a nada tan maravilloso... Comer teta como parte final de la comida es algo que predispondría quizá más a la siesta (Weinrichter, 1992: 87).

Cuando Bigas Luna proponía esta deliciosa conexión no estaba siendo del todo original, simplemente se hacía eco de algo que, de alguna forma, todos intuimos. Sexualidad y gastronomía son actos esenciales para el ser humano. "El erotismo es al sexo lo que el gusto a la comida. No hacemos el amor como los animales" "y tampoco comemos como ellos" afirmaba con firmeza el cineasta "lo hacemos sobre una mesa, con un mantel, [y con] unos adornos" (Sánchez, 1999, p.91). Como para el resto de los animales, necesitamos comer y reproducirnos para contribuir al mantenimiento y subsistencia de la especie. Sin embargo, el

\footnotetext{
${ }^{2}$ Según propia confesión del cineasta en el documental Bigas $X$ Bigas (Bigas Luna y Santiago Garrido Rúa, 2016).
} 
goce que obtenemos saciando nuestros apetitos alimenticios y sexuales es muy distinto. Atendiendo sus urgencias fisiológicas, el ser humano ha sido capaz de transformarlo en puro placer. "Si los animales solo copulan en las etapas de celo de la hembra, comen cuanto tienen hambre, beben para saciar su sed y no son capaces de elaborar alimentos para su consumo, el hombre ha convertido estas dos actividades básicas, de pura supervivencia, en dos manifestaciones básicas de su propia cultura" (Cavalieri, 2015, p.27) y son actos que, gracias a la intervención de la imaginación, están cargados de significación y dotados de un gran valor simbólico y estético en la vida de los seres humanos.

Ya en el Cantar de los Cantares, cuando el amante describe a su amada exclama: "Y que tus senos sean racimos de uvas, y tu aliento el aroma de las manzanas, y tu boca el mejor vino mojándome los labios y los dientes”. Prueba de que nuestra cultura ha percibido la afinidad que existe entre estas dos actividades, es la cantidad de metáforas, vocablos y expresiones gastronómicas con un alto contenido sexual. No es casual que un término como "apetito" no sólo posea connotaciones culinarias, sino también lo utilicemos para referirnos al hambre o necesidad del alimentarse del otro, de la cual derivan expresiones tan vívidas como "devorarse con los ojos", "comerse a alguien a besos" o "estar consumido por los celos". De una persona se puede decir que tiene "ojos almendrados", "labios carnosos", y una tersa y suave "piel de melocotón". Así también para referirse al esparcimiento obtenido en los escarceos previos se utilizan las expresiones "darse el banquete" o "pegarse el filete" y hay además "comecoños", "comechochos", "comealmohadas" y para adjetivar a la mujer de gran apetito se utiliza la expresión "devorahombres". Por el contrario cuando de los prolegómenos se pasa a la acción entonces se dirá que se "pincha el cangrejo", se está "comiendo el pan de higo", "dando de beber al conejo", "enterrando la sardina", "mojando el churro" o "poniendo los huevos a calentar". Al pecho femenino además de recibir los apetitosos apelativos de "cántaros de miel" o "restaurante", también se le asocia con una gran variedad de frutas que, en función de su tamaño, pueden ser desafiantes "peras", deseables "naranjas", exuberantes "melones" o voluptuosas "sandías". A la muchacha de buen ver se le dice "jamona" o también que es una "perita en dulce", si es un muchacho agraciado y sexualmente atractivo entonces se le 
aprecia porque "está más bueno que el pan” o porque es un “yogurín”. No se escapan de esta gran riqueza léxica gastroerótica que ofrece nuestro idioma ni el sexo femenino ni tampoco el miembro viril. Al primero encontramos asociados términos como "albaricoque”, "patata”, “perejil”, “conejo”, “castaña”, "chocho", "higo", “ostra”, "almeja” o "peladilla” y al segundo se le suele asociar con el popular "plátano", pero también con productos de la tierra como el "boniato", el "nabo", el "pepino", la "cebolleta", la "berenjena" y el "haba", o con vocablos de índole charcutero tales como "morcilla", "chorizo", "salchicha" y “salchichón”. Por todo esto no es extraño que el arcipreste de Hita, allá en el siglo XIV, escribiera estos jocosos versos en el prólogo a su Libro del Buen Amor:

Aristóteles dijo, y es cosa verdadera, que el hombre por dos cosas trabaja; la primera por el sustentamiento, y la segunda era por conseguir unión con hembra placentera.

Es el banquete amoroso por tanto, un toque de arrebato para todos nuestros sentidos. A través de ellos conocemos, comprendemos hasta qué punto nos gusta la persona deseada y nos predispone a un consumo posterior, de más alcance, mucho más íntimo. De alguna manera, saborear un alimento "es una reproducción del acto sexual. En ambos casos se trata de oler, mirar, tocar, lamer, morder, libar.” (Cavaliere, 2015, p.32). Zapadores son la vista y el olfato que abren el camino del amor a todos los demás. Primero es el tiempo de las palabras susurradas al oído, después se aproxima con tiento el desesperado tacto para terminar entregado a los dulces y revoltosos besos. Sostenía BrillatSavarin en su ensayo titulado Fisiología del gusto escrito en 1826 que, además de muchas otras cosas, el gusto "acrecentaba las delicias del amor" (BrillatSavarin, 1978, p.60) estableciendo con ello un primer punto de relación entre los placeres de las sábanas y el mantel. Y es cierto que en la cama y en la mesa, de todos los sentidos el gusto es el soberano. 


\section{Un bufé gastroerótico muy particular}

En su obra cinematográfica Bigas Luna cultivó su sitofilia con la constancia y paciencia de un buen agricultor3. Desde luego no ha sido el único. Muchos directores, antes y después que él, han utilizado la relación que existe entre el mundo culinario y el erotismo. Quizá la forma más recurrente ha sido la de subrayar el poder afrodisiaco que tradicionalmente se les ha conferido a ciertos alimentos. Así ocurre, por ejemplo, con la delicada receta de codornices en pétalos de rosas que Tita prepara en Como agua para chocolate (Alfonso Arau, 1992) y que desata el lujurioso frenesí entre sus invitados. En otras películas, los restaurantes, mesones o cafeterías se han mostrado como espacios propiciadores de futuras intimidades. En la adaptación fílmica que, de la novela Tom Jones de Henry Fiedling, llevó a cabo Tony Richardson en 1963, una de sus secuencias más celebradas es aquella en la que el protagonista comparte mesa con la señora Waters en una taberna y lo que comienza siendo una inocente cena termina derivando, gracias al sensual manera de tomar los alimentos y a las prometedoras miradas que intercambian, en un lúbrico juego de insinuaciones y de incandescentes provocaciones. Algo parecido ocurre en Flashdance (Flashdance, Adrian Lyne, 1983) en la que una langosta es utilizada por la joven bailarina Alex Owens para embelesar a su compañero de mesa. En otros filmes, los restaurantes han sido utilizados como marco donde el sexo se muestra de una forma más o menos velada. En algunos casos, el almuerzo de dos amigas en un comedor universitario sirve para ofrecer, utilizando las zanahorias de la guarnición, una lección práctica de cómo hacer una buena felación -Aquel excitante curso (Fast Times at Ridgemont High, Amy Heckerling, 1982) - o para demostrar la capacidad de fingir un ruidoso orgasmo -Cuando Harry encontró a Sally (When Harry Met Sally, Rob Reiner, 1989)-. En Sashimi (Sashimi, Pan Chih-Yuan, 2015), el cocinero protagonista es especialista en preparar para sus clientes más sofisticados sugerentes manjares sobre una mujer desnuda. En otros filmes, tales como Nueve semanas y media (Nine 1/2 Weeks, Adrian Lyne, 1986), Tampopo (Juzo Itami, 1985) y de una forma más paródica en Hot Shots! (Jim Abrahams, 1991), la comida se presenta

\footnotetext{
${ }^{3}$ Se denomina sitofilia a la excitación sexual obtenida gracias al uso de alimentos con fines eróticos o como un elemento de los juegos sexuales (Rodríguez González, 2011, p.970).
} 
como una base segura para la seducción, como un rito preparatorio de los placeres íntimos que se avecinan. No obstante, en ocasiones, la combinación sexo y alimentación no da los resultados deseados como le ocurre a una de las protagonistas de la comedia adolescente Juego de campeones (Varsity Blues, Brian Robbins, 1999), en la que sus esfuerzos por seducir a un compañero de instituto se ven frustrados pese a presentarse frente a él casi desnuda, sólo cubriendo, con falso pudor, su pubis, pecho y pezones con cerezas y abundante nata montada. Por otro lado, hay cintas en las que la vagina se traspone por una sandía -El sabor de las sandía (Tian bian yi duo yun, Tsai Ming-liang, 2005) -o es sustituida por un prosaico pastel de manzana con fines masturbatorios American Pie (Paul Weitz, 1999). Hay también, por último, algunas películas, donde los alimentos forman parte integrante del acto sexual. Esto pasa con el huevo duro que introduce amorosamente Kichizo Ishida en la vagina de su amante Sada antes de comérselo en El imperio de los sentidos (Ai no korîda, Nagisa Ôshima, 1976), la harina en la tórrida escena que interpretan Jessica Lange y Jack Nicholson sobre la mesa de la cocina de El cartero llama dos veces (The Postman Always Rings Twice, Bob Rafelson, 1982) o en el intercambio de parejas de Four Lovers (Happy Few, Anthony Cordier, 2010). En La vida es dulce de Mike Leigh (Life is Sweet, 1990), el torso desnudo de una muchacha atada al espaldar de la cama, se muestra cubierto de chocolate mientras es lamido y chupado por su novio. Otro tanto ocurre, en La gran comilona (La grande bouffe, Marco Ferreri, 1973), los cuatro amigos entremezclan a lo largo de su culinario suicidio el sexo obsceno con el pudin de pescado, los quesos, los jamones, las tartas de crema y el caviar4.

Pero entonces ¿dónde radica la originalidad de Bigas? Desde luego este juego de correspondencias entre alimento y sexualidad no fue algo puntual en su filmografía. Si se analizan detenidamente sus películas se puede rastrear en casi todas ellas -quizás la excepción que cumple la regla sea Renacer (Reborn, 1981)-, las huellas de esta obsesión. Y en este sentido, la obra de Bigas Luna es

\footnotetext{
4 A esta relación habría que añadir la muy heterodoxa, original y afortunadamente incorrecta $L a$ fiesta de las salchichas (Sausage Party, Conrad Vernon y Greg Tiernan, 2016). En un mundo de alimentos antropomorfizados e hipersexualizados, el filme nos narra las aventuras de Frank, una salchicha seductora, y Brenda, un panecillo para perritos calientes con formas que recuerdan a una vagina.
} 
única. Tal y como apunta Maurizio Fantoni (2000, p.43), en sus personajes el deseo sexual está íntimamente enlazado con el instinto de supervivencia aunque también con el de muerte-, pero esta relación no se percibe desde el primer instante, ni tampoco se muestra estática a lo largo de toda su obra. Al mismo tiempo que en su cine se depuran sus formas y sus temas, también evoluciona su concepción de la relación entre sexo y alimentos. Podría decirse que, al igual que la luna, su cine transita por distintas fases: de la luna negra a la luna llena. Al principio apenas se intuyen sus perfiles, el tema está apenas esbozado, después se oscurece, la relación entre sexo y alimentos es grotesca, turbia y bizarra en su primera trilogía, pero poco a poco se aclara, en su etapa ibérica o roja se torna más mediterránea, luminosa y lúcida, es allí donde alcanza su máximo esplendor, su máxima expresión para a continuación, en sus últimos filmes, volver a apagarse gradualmente.

En Tatuaje (1976), a pesar de haber sido realizada todavía bajo la estricta supervisión de la censura franquista 5 , el universo gastroerótico de Bigas Luna aflora tímidamente, todavía impreciso. No deja de ser sintomático que para su primera incursión cinematográfica optase por la adaptación de una novela protagonizada por un detective gourmet. Con Charo, una prostituta del El Raval, Pepe Carvalho mantiene una estrecha relación. Es su confidente y amante. Cuando ella limpia los platos, el aprovecha para propinarle unos cariñosos azotes y sopesar con la mirada sus prietas nalgas. Más adelante guisa para ella y una compañera de profesión, interpretada por Terele Pávez, y en la sobremesa mientras las interroga sobre una sospechosa, el ambiente se va caldeando hasta que la amiga de Charo termina, juguetona, mostrándole sus deleitables senos. Mucho más explícito se muestra en uno de los cortos pseudoporno que rodó tras el fracaso de su primer filme, y que lleva por título $E l$ desayuno (1977). En la cocina de una casita de montaña, una joven rubia se

\footnotetext{
5 Bigas Luna nunca quiso hablar demasiado de su opera prima, rehusaba amablemente hablar de ella y culpaba de su fracaso comercial, no sólo a su inexperiencia en el campo cinematográfico, sino también "estuvo tres meses parada en censura porque en el diálogo se decía coño o porque se veía un pene en un cuadro" (Miñarro, 1978, p.17). Para mayor abundamiento en torno a las vicisitudes de la película a su paso por Junta de Calificación y Apreciación de Películas, basta consultar el expediente de censura que se conserva en el Archivo General de la Administración.
} 
prepara para comenzar el día con buen pie. Tras calentarse la leche y poner un LP en un tocadiscos, se sienta en la mesa para disfrutar de su primera comida. Mientras suena el tema de la película Las rojas noches de Harlem (Shaft, Gordon Parks, 1971), mezcla de soul y funk, toma galletas con mermelada hasta que, víctima de un inesperado ardor, se desabrocha su camisa a cuadros para mostrar lo que oculta su generoso escote. Transportada por voluptuoso frenesí unta sus pechos con mermelada de fresa y melocotón, chupa sus dedos embadurnados y termina casi desnuda, sólo con medias, masturbándose con desvergonzada sensualidad.

En su primera trilogía, la más oscura y racional, también la más radical en sus formas y estilo, los objetos -y entre ellos la comida, los alimentos- están puntuando los lóbregos, amorales y sórdidos caracteres de sus personajes. Como acertadamente señala Ramón Espelt, una de las características más reiteradas en estas películas es la presencia de un personaje principal masculino inmerso en una estructura familiar en la que el padre no tiene apenas relevancia o simplemente está ausente, y en la que existe un predominio absoluto de la figura materna con la que, estos niños grandes, mantienen un tira y afloja emocional y psicológico (1989, p.48). En el caso de Leo, el psicópata fetichista de Bilbao, es clara su absoluta sumisión hacia María, una mujer madura y posesiva. "A veces pienso que es la única persona que soporto" musita Leo, “pero estoy cansado de ella. Han pasado muchas cosas". En sus encuentros íntimos nunca hay coitos, solo masturbaciones recíprocas donde los alimentos juegan un papel singular a modo de metáforas de un deseo sexual reprimido, incapaz de aflorar de manera natural, incapaz de consumarse del todo. Así se sugiere en dos escenas importantes que transcurren en dos espacios, muy queridos por Bigas, como son el comedor y la cocina. En el primero, Leo y María se sientan a la mesa; sobre ella hay dispuesta una botella de leche, un trozo de pan, una bandeja con menestra de verduras coronada con media salchicha, y una fuente con plátanos, manzanas y naranjas. Hasta que no le sirven su plato, él sigue embebido recortando noticias e imágenes referidas a Bilbao. María coge entonces la salchicha y, de manera provocativa, comienza a chuparla. Sin dejar de hacerlo, se levanta, se acerca hasta él, se agacha, le abre la bragueta y lo acaricia. Leo permanece imperturbable en todo momento, cierra los ojos y se 
deja llevar. La segunda escena transcurre en la cocina, María ha preparado un vaso de leche caliente, reclama la presencia de Leo y este, que sabe lo que ella quiere, acude dócilmente. Ella lo recibe de espaldas y él le desabrocha la falda para poder acariciarla como a ella le gusta. Leo sigue pensando en Bilbao, pero cumple con lo que parece un ritual íntimo de modo diligente. María le introduce sus dedos en la boca y él acaba derramando la leche del vaso en sus nalgas desnudas que baja presurosa por su medias negras hasta llegar a sus zapatos. Pareciera que el tedio y la rutina han transformado su relación, convirtiéndola en algo más sórdido, más insoportable. A lo largo del filme, Leo a lo largo del filme trata de liberarse de estas ataduras, pero sus actos de rebelión son menudos, infantiles, sin consecuencias. Le escupe en el vaso de leche, apenas dialogan, no se miran, desoye sus requerimientos y reproches, pero al final, cuando llora desconsolado en su regazo por la muerte de Bilbao, es ella la que, con actitud decidida, le ayuda a desembarazarse del cadáver de la prostituta.

No menos escabrosos y desvergonzados son los lazos que mantienen unidos a los dos hermanos huérfanos protagonistas de Caniche. El incesto y la zoofilia se dan la mano para ilustrar una idea que Bigas mantuvo a lo largo de toda su vida: "la belleza y el amor pueden ser comidos" (Pisano, 2001, p.182). Efectivamente, inspirándose en una anécdota que le relató el propio Salvador Dalí6, Luna concibió esta historia de amor y celos enfermizos. Tanta es la obsesión por los perros que les profesan Héctor y Eloísa que sólo se alimentan con su carne y, para prevenir enfermedades, prefieren recoger tiernos cachorrillos, libres de toda duda, para preparar deliciosos estofados7. Mucho más elusivas son las

\footnotetext{
${ }^{6}$ Así al menos lo relató Bigas Luna a Cayetana Guillén Cuervo en el programa Versión española de TVE: "El inicio del cuento de Caniche aparece a través de una historia que me contó Dalí, que me dejó sorprendidísimo y en ese momento estábamos escribiendo Caniche, y esto fue un poco la fuente de inspiración. La historia es que, antes de que empezara la guerra, él y Gala se tenían que ir, se iban a Francia, y tenían un gatito al que adoraban, era su animal más querido, y ella la noche antes de irse, lo mató y lo coció. Hizo gatito. Y esto lo contaba, la primera vez que veo a Dalí contar una cosa... porque la típica boutade de Dalí sería decir: «No, no, yo me lo comí». Pero no, él lo contaba asustado y dijo que no se lo pudo comer. Y Gala sí. Eso me impresionó. De hecho, esa frase de que si quieres a alguien, te lo comes, y que es verdad, y que es una cosa que la puedes coger como terrorífica o no, como un acto conceptual que es un acto de amor. Eso me impresionó mucho. $\mathrm{Y}$ entonces, a partir de este pequeño relato fue donde empecé a escribir Caniche, este cuento para adultos que nadie, cuando la vea, debe tomar como una historia realista, sino que intente especular en lo que podría ser un cuento para adultos"

7 Bigas volverá a utilizar una variante de esta idea sugerida por Dalí en 1992, en Jamón, Jamón. Las hermanas de Silvia cuidan con esmerado cariño un lechoncito llamado Pablito. Cuando éste muere víctima de un trágico accidente provocado por la moto conducida por Raúl, la madre de
} 
metáforas gastronómicas utilizadas por el director en la película que cierra esta trilogía, Angustia (1987). También aquí el protagonista vive en un mundo dominado por su madre que lo utiliza, por medio del hipnotismo, para sus particulares actos de venganza. Para ilustrar que el espectador se encuentra ante un hombre psicológicamente castrado, sin iniciativa, cuya voluntad se encuentra en manos de su progenitora, Bigas lo hace aparecer cortando frenético un plátano, sobre un tazón de leche, chupándose ruidosamente los dedos y bebiendo leche a gallete de un porrón de cristal $^{8}$.

Después de la lóbrega intensidad de sus primeros filmes, Bigas comienza a apuntar hacia una nueva dirección. Sin traicionar del todo los rasgos más potentes de sus anteriores películas, el cineasta se apresta ahora a encontrar el deseado y necesario punto de equilibrio para conjugar comercialidad con su singular poética personal. En ese sentido, se puede considerar que con Lola (1986) y Las edades de Lulú (1990) se produce esa inflexión, son dos obras de transición hacia su trilogía ibérica, son dos obras con las cuales el cineasta romancea hacia posiciones más vitales y optimistas. "Lo más que me interesa cuando creo", llegará a decir más adelante en el filme documental Bigas X Bigas (Luna \& Garrido, 2016), “es dar ganas de vivir”. Hay en él y en su cine una actitud mucho más integradora, más comprensiva, más abierta: “Optimismo quiere decir apertura; es necesario hacer sentir las ganas de vivir, su pulsión; es por esto por lo que en mi cine la comida y el sexo son centrales... Deseo de vivir, porque follar y comer son funciones vitales, y si renuncias es como disminuir la energía que nos empuja hacia delante. Yo quiero sentir esta energía y transmitirla” (Pisano, 2001, p.194). En esta nueva etapa de cine más biofílico, el nexo entre sexo y gastronomía se transforma, se vuelve más patente. Ya no sólo

las niñas decide que, en lugar de enterrarlo, será mejor utilizarlo para hacer tocinillo de cielo con nata.

8 El uso de un porrón de cristal para beber leche es una constante en su cine. Volvería utilizarlo, con otras connotaciones, en La teta y la luna (1994). Según el cineasta el origen de este elemento tan personal de su universo creativo se encontraba en una experiencia de la infancia: "Cuando cumplí nueve años, contraje una enfermedad de la que jamás he vuelto a oír hablar: el paratifus. No podía comer prácticamente nada, tenía la garganta muy inflamada y me alimentaban exclusivamente de suero y leche, que debía beber a chorro. Esto suponía una lucha violenta entre yo, mi madre y mi tía Paulina, que me obligaban a abrir la boca para lograr hacerme entrar el chorrito de leche que caía del porrón mientras yo hacía lo posible para evitarlo. La leche se derramaba cayendo sobre mi cara y mi cuerpo, mojando finalmente todas las sábanas. Tengo un recuerdo escalofriante de esos tiempos. Desde entonces no he vuelto a probarla." (Pisano, 2001, pp.39-40) 
constituye una breve pincelada, puntual y breve, que enriquecía la caracterización psicológica de sus personajes, sino que se convierte en un elemento central y aglutinador de sus tramas porque entiende el realizador que esta peculiar relación entre erotismo y comida es una parte consustancial a la cultura ibérica, algo que estaba profundamente enraizado en nuestras bases étnicas. Algo que Bigas Luna pone de relieve cuando en Huevos de oro (1993) Gil, el empresario que va a financiar las veleidades arquitectónicas de Benito, relaciona la proverbial y legendaria mala leche del español con su tradicional afición a los garbanzos.

Esta revelación sucede después de cuatro años de estancia en EEUU, allí el cineasta sufre una suerte de epifanía personal e identitaria. En la distancia descubre su país natal y una cultura que comienza a contemplarla con otros ojos. En el catálogo publicado en 1992 bajo el título Bigas y Luna para el Festival de Cine de Gijón, el director recordaba aquel momento revelador:

La primera vez que pude observar desde fuera este país, cuando tenía veinte años, fue gracias a un amigo inglés Richard Wentwoth, que estaba pasando unos días aquí, me dijo que una de las cosas que más le sorprendía era que tuviéramos "piernas de animales", colgadas de los techos en los bares. Desde entonces empecé a darme cuenta de que vivía en una realidad que estaba muy cercana al surrealismo y empecé a fascinarme por cualquier cosa que representara nuestra cultura"(AAVV, 1992, p.61).

Sin duda la gastronomía forma una parte importante en el proceso de elaboración de nuestra identidad cultural. El jamón, el ajo, la tortilla, la paella y el aceite nos definen como pueblo. En ese sentido acierta Carolina Sanabria cuando afirma que en

tanto que construcción social, la satisfacción del apetito parte de un imaginario y una ritualidad que en la cultura española se vincula con la sensualidad (...) Pero la propuesta de Bigas se dirige a una concomitancia más directa con el erotismo. Comida y sexo derivan en la consumación de un placer: ambas retienen al hombre como un ser no solo de necesidades, sino de instintos (Sanabria, 2010, p.64). 


\section{La boca, los pies, el jamón, los huevos y la leche}

Si utilizamos una aproximación temática de su cine, Bigas se nos revela como un creador obsesivo y constante, se le adivina con facilidad su trazo firme en cualquiera de sus películas. Un objeto fuera de lugar, un detalle de insignificante apariencia, una imagen fugaz se constituyen en la trama y la urdimbre no sólo del argumento concreto de cada una de sus películas, sino también de un coherente y potente universo cinematográfico. La crítica nunca le perdonó que, en aras de la comercialidad, abandonara el camino radical que inauguró con sus primeros filmes. La sombra de Bilbao, Caniche y Angustia fue para el siempre oscura y alargada. Pero Luna nunca fue un creador dócil, antes al contrario, en comparación con otros directores coetáneos, fue un artista que supo zurcir toda su filmografía con un repertorio iconográfico original y consistente. Sus películas están salpicadas con cientos de potentes imágenes metafóricas donde consiguió plasmar con belleza e imaginación sus obsesiones más íntimas. Sólo se necesita un ojo atento para identificarlas.

De tener que hacer un mapa iconográfico del universo de Luna, encontraríamos que este está plagado de motivos visuales, personajes, temas y escenarios que se despliegan en el espacio como una estructura fractal, estableciendo entre ellos una red de múltiples correspondencias y abundantes relaciones. No se pretende elaborar aquí un inventario completo y exhaustivo de todas sus metáforas, símbolos y analogías, pero sí ofrecer un muestrario significativo de algunas de las figuras retóricas utilizadas por Bigas Luna a lo largo de su carrera. Desde luego, las más poderosas son justo aquellas que se relacionaban la erótica sensualidad con la gastronomía. Una de las más famosas y comentadas la planteó en Bilbao, cuando su protagonista, después de haber disfrutado de los servicios bucales de la prostituta y como recuerdo de este primer contacto, construye en el lavabo de su cuarto de baño, con un pescado y media salchicha, un objet trouvé que habría hecho las delicias de dadaístas y surrealistas. Pero el cineasta pronto descubrió que, entre comida y eros, además de estar enlazadas por ser ambas fuentes de placer primario, además de estar indisolublemente unidas por analogías que iban mucho más allá del puro significado metafórico, sus íntimas relaciones habían moldeado y hundían sus raíces en lo más 
profundo de la cultura mediterránea. Esta convicción de Luna quedó plasmada magistralmente en Huevos de oro, en aquella secuencia donde Benito González, por azar, encuentra a Claudia en un chiringuito de playa en Benidorm. En ella, mientras el protagonista y su amigo el Mosca devoran bogavantes y planean su futuro como constructores de rascacielos, sobre una mesa vecina y al son del Achilipú cantado por Dolores Vargas, Claudia ofrece un espontáneo baile para los miembros de un equipo deportivo local. Antes de descalzarse, un primer plano permite contemplar el tacón de su zapato banderilleando un trozo de pan y como con su pie desnudo esparce el contenido de un palillero. Sus sensuales contoneos alrededor de los restos de una paella son recibidos con vítores y requiebros de los comensales. Sin dejar engullir y masticar con la boca abierta, Benito la admira en la distancia -"mira, mira... está buenísima. iJoder, mira qué culo!", le dice a su compañero-y la devora con los ojos: "A mí cuando veo a una tía buena me pasa como al bogavante, me ponen una gomita y me la como toda”. El personaje de Claudia representaba para Bigas Luna, la espontánea sensualidad mediterránea de una mujer débil, intuitiva e irracional. Con su improvisado espectáculo de sobremesa, el realizador nos ofrece su versión castiza de esa peculiar costumbre japonesa denominada nyotaimori donde, sobre una muchacha desnuda que actúa como plato, diversos comensales disfrutan de distintas viandas.

En el cine de Bigas Luna hay asimismo una serie de motivos visuales que, de un modo recurrente, aparecen en sus películas y que, en ocasiones, tienen que ver con experiencias personales del propio artista. Una de ellas, con la que quizás apuntaba a la voluptuosa naturaleza de sus personajes femeninos, es la de presentarnos, en ocasiones en primer plano, a sus mujeres comiendo algo de un modo ostentosamente erótico9. De esta manera, unos labios casi siempre pintados de un rojo intenso y cautivando un fálico chorizo o una salchicha, se convierten en trasuntos de aquellos otros que encendidos permanecen ocultos bajo la ropa íntima. Así ocurre con la pipa de melocotón que, en Lola, la protagonista chupa y después entrega a las dalinianas hormigas, con los churros

\footnotetext{
${ }^{9}$ En el documental Bigas $X$ Bigas, cuenta cómo se enamoró de Celia Oros, su segunda mujer: «Celia cocina muy bien, pero me enamoré de ella cuando la vi cómo se comía una ostra, la comía con una delicadeza que pensé: "esta mujer debe ser una maravilla, seguro". Y no me equivoqué»
} 
que, en Las edades de Lulú, Pablo le ofrece a su joven amante, los espaguetis que Valeria Marini prueba en Bambola (1996) o la naranja que muerde y sorbe Marina en Son de mar (2001), mientras tumbada y en braguitas lee distraídamente una revista. En La teta y la luna la metáfora es mucho más lírica y elocuente. Cuando Maurice, agobiado por no poder complacer a su bella Estrellita, quiere reafirmar su virilidad la obliga, a modo de culinaria felación, a “jugar a la baguete”. En otras películas, esta metafórica correspondencia se invierte y son determinadas partes del cuerpo de los amantes los que son degustados como si fueran alimentos. En Yo soy la Juani (2006), por ejemplo, la protagonista besa y lame la nuez de adán de su chico mientras le susurra: "Me gusta besarte aquí, es como una polla" y él le confiesa excitado: "Se me está poniendo dura”. También ocurre con los dedos de la mano cuando Horty fabula su primer encuentro con La camarera del Titanic (1997) o lo de los pies -en una imagen que parece extraída de La edad de oro (L'âge d'or, Luis Buñuel, 1930), en Volaverunt (1999) y en La teta y la Luna cuando Estrellita chupa ávida el pulgar de su marido para extraer el aroma a coliflor, a cruasán caliente y a queso roquefort así revelando su origen francés. "Para mí los pies son algo religioso, es como una obsesión. Los pies no sé por qué me hacen pensar en la religión. No me preguntes más, será un cuadro que vi de pequeño, el clavo en el pie de Cristo, no sé” (Weinrichter, 1992, p.84). Quizá la concomitancia más conocida y que ilustra el carácter diferenciado de los dos muchachos que se disputan el amor de Silvia, se encuentra en Jamón, Jamón. En dos momentos distintos de la trama ambos disfrutan de los senos de la protagonista. Para Raúl, encarnación del macho ibérico, poseedor de una sexualidad desbordante, sus tiernos y prietos pechos adolescentes saben a "jamón, tortilla de patatas, cebolla y ajo”. Para José Luis, pánfilo, débil y apocado, no saben a nada. Mientras el primero los saborea, chupa y se embriaga con ellos, el segundo se aproxima a ellos como un bebé, tiernamente, sólo para amamantarse.

Precisamente es con esta obra con la que Bigas abre su trilogía roja o ibérica, un tríptico cinematográfico, donde resume lúcidamente su concepción del erotismo y sus vinculaciones con la gastronomía. En esta ocasión esta relación no se plantea como algo meramente anecdótico, puntual, sino que se convierte en un elemento sustancial de su discurso. Estos tres retratos fílmicos tuvieron un hilo 
conductor común, son las estampas de una España "profunda y testicular" (Sanabria, 2010, p. 70) con sus fetiches, iconos y tradiciones. Este retrato racial hilvanado con un eje culinario común que va desde el jamón hasta la leche pasando por los huevos con chorizo. Es el jamón, por un lado, el símbolo de una España atávica, ancestral, ensimismada y rural, de amores desgarrados y tragedias delirantes, un país que, dominado por las moscas ${ }^{10}$, que sabe y huele a ajo y a tortilla, un país que marcando paquete y cojones juega con los toros a la luz de la luna y que está habitado por chicas "jamonas" que, arrebatadas y pasionales, exudan sensualidad por todos los poros de su piel. Pero también está esa otra España que quiere incorporarse a la modernidad a su manera, a golpe de talón y máquina excavadora, patria del macho ibérico, chulo, vulgar y hortera que mezcla en su indigesta dieta el marisco, los étnicos huevos con chorizo y el turrón de Alicante. Y estaría, por último, una España vista con ojos infantiles, de perfiles más finos y evocadores, que es regazo y protección, madre y voluptuosa nodriza, una fabulosa matrona que, junto al Mediterráneo, amamanta a su prole con sus senos cargados de leche.

\section{En el tierno regazo de una allattatrice}

Por encima de todos los otros motivos iconográficos, en el mundo creativo de Bigas Luna sobresale uno especialmente, aquel que tiene que ver con los senos femeninos y que, curiosamente, aúnan las dos vertientes que más le interesaban: sexo y gastronomía. No era en esto nada original, pues es posiblemente la parte del cuerpo de la mujer que mayor atención erótica ha recibido por parte de los varones, quizá porque "enfocar una atención extrema sobre los genitales sería excesivo y hacerlo sobre otras partes de la anatomía es insuficiente. Los pechos son en cambio el perfecto término medio: una zona tabú, pero no demasiado escandalosa" (Morris, 2004, p.171). El cineasta reconocía que esta obsesión, de resonancias edípicas, hundía sus raíces en su

\footnotetext{
10 Para Bigas la presencia de una mosca era signo indiscutible de calidad de vida "porque en los países muy civilizados, que todo está demasiado limpio, la fruta está verde para que sea bonita, no hay ni una mosca. Entonces la comida no tiene sabor. Si hay una mosquita entonces quiere decir que la fruta está madura, que la cosa está mucho mejor. Entonces si hay muchas moscas entonces la miseria es tremenda y no deseable. Solo una mosquita no está mal, es el equilibrio" (Programa El faro de Alejandría, RTVE, 2003).
} 
propia infancia. Como muchos temas que rondaron su cabeza, esta fascinación mamaria tenía que ver con algún recuerdo o experiencia vital personal:

Estaba enamorado de mi madre. Era una mujer muy vaporosa; no, es más justo decir que era un ser alucinante. Con grandes pechos, siempre muy arreglada, elegante, una gran seductora. De pequeño estaba convencido de que los pechos de las mujeres estaban llenos de leche. Cuando mi madre me cogía entre sus brazos y me apretaba contra sus enormes pechos, me aterrorizaba pensando que la leche empezaría a salir y a mojar mi cabeza. Para protegerme, escondía mi cabeza debajo de sus axilas." (Pisano, 2001, p. 39).

Fue más tarde cuando descubrió que en realidad no estaban llenos de leche. Un descubrimiento que convirtió una experiencia agradable y sensual en la primera decepción de su vida:

El paso (...) de mi fantasía infantil, a la adolescencia fue a través de dos tetas. Tenía doce o trece años y me encontraba en un pueblo de veraneo en Malgrat de Mar. Ella tendría veintidós o veintitrés años y era alemana. Como puedes imaginar, fue estupendo; por un lado, era muy placentero poder tocar con una cierta lascivia, pero por otro fue una gran decepción comprobar que aquello no estaba lleno de leche. Fue como descubrir otro mundo. Imagínate lo que sentí cuando te conocí; creí que eras una pastelería. (...) En realidad, cuando cogí en mis manos las tetas (que imaginaba llenas de leche) de la alemana; cuando terminé de tocarlas, el que estaba mojado era yo... (...). La leche cambió de sitio (Pisano, 2001, p. 44-45).

Esta particular vivencia del cineasta se vio reflejada, de una forma lírica y emotiva, en la película que, con un tono felliniano, cerraba su trilogía ibérica: La teta y la luna. En ella el protagonista es Teté, un niño de nueve años de imaginación desbordante que se siente destronado cuando nace su hermano y acapara la teta, henchida de leche, de su madre. Obsesionado con tener una teta sólo para él, le pide a la luna que le conceda ese único deseo. Es entonces cuando llega a su pueblo una compañía ambulante de artistas donde trabaja Estrellita, una joven portuguesa y su esposo Maurice. Un día, cuando la muchacha está ensayando su número, Teté escondido entre bastidores contempla fascinado su pecho desnudo de apetitosos pezones y se enamora perdidamente de la artista. Desde aquel momento no parará hasta conseguir 
que la artista acceda a, oprimiendo su seno, ofrecerle la leche que su madre le niega. Tanto es el empeño del chiquillo que, en una de las secuencias más hermosas de toda su filmografía, Estrellita conmovida libera uno de los pródigos senos que, como un porrón mágico de buena hechura, surten generosos de leche la boca del pequeño. Fue esta la primera vez que Bigas Luna sirviéndose de la imaginación de Teté representó en el cine una allattratrice, una "constante en la sucesiva creación visual de Bigas" (Sanabria, 2010, p.83), inspirada en la singular iconografía religiosa de las vírgenes lactatio. La representación de la diosa que amamanta o deja fluir la leche de sus pechos es tan antigua como universal. Las representaciones de la diosa Isis amamantando al dios Horus son relativamente frecuentes en el arte egipcio, una iconografía que se ha relacionado, como precedente, con la figura de la Virgen ofreciendo su seno inmaculado al Niño. En la tradición cristiana, especialmente a partir de la Edad Media, la leche de la Virgen María es considerada un vehículo de salvación por eso aparece representada, "no sólo amamantando al Niño, sino también ofreciendo su leche a los fieles, refrescando con ella a las almas del purgatorio o premiando con el lácteo licor a algún personaje, especialmente San Bernardo, que por su devoción se hace acreedor de ese privilegio” (Blaya, 2008, p. 106). Para Bigas fue toda una revelación descubrir en uno de los claustros de la Catedral de Tarragona una figurita, de apenas un metro de altura, en la que se representaba a una Virgen María “feliz, sensual y mediterránea”, sonriendo mientras el niño Jesús se afana por mamar del pezón sonrosado de su madre ${ }^{11}$.

Fascinado por esta figura, Bigas no tardó en hacerla suya, convirtiéndola en un elemento constante en su mitología personal. En la etapa final de su carrera, su universo creativo se puebla así de generosas y voluptuosas allattatrices que sorprenden al espectador ofreciendo, en ocasiones, su divino y lácteo licor al Mediterráneo, en otras descargándolo contra el cielo, sirviéndolo caritativamente a gente necesitada, o incluso bebiendo de su propio pecho. Luna

${ }^{11}$ Para ser precisos, la secuencia de La teta y la luna en la que Teté es amamantado en la distancia por Estrellita está inspirada en una modalidad de esta iconografía, concretamente la conocida como La Lactación de San Bernardo (Ver Rafael Durán, Iconografía de San Bernardo, Monasterio de Poblet, Barcelona, 1953). Al final de la película, cuando Teté consigue superar su miedo a coronar un castell durante las fiestas de su pueblo, como onírico premio no solo podrá lactar directamente del pecho de Estrellita, sino también recuperar el tierno seno de su madre. En este caso, sí que la iconografía utilizada es la de la Virgen Lactante. 
trabaja de modo tan obsesivo esta iconografía de la madre nutricia que, como no podía ser de otro modo, pronto se manifestó también en otras facetas artísticas que el cineasta había continuado cultivando en paralelo a su carrera cinematográfica. En el año 1995, por ejemplo, presentó ocho dibujos de estas mujeres lactantes realizados sobre páginas arrancadas de sus antiguos guiones cinematográficos en la galería Santo Ficara de Florencia y, un año más tarde, organizó una performance para un escaparate de la galería Giulia de Roma con siete allattatrices que, a lo largo de una semana y de forma puntual cada día a las seis de la tarde, mostraban durante unos segundos sus pechos cargados de leche a los viandantes (Pisano, 2001, p. 217). En el campo cinematográfico, Bigas tendrá la oportunidad de volver a utilizar este motivo en el filme colectivo titulado Lumière y Compañía (Lumière et compagnie, 1995) que, con motivo de la celebración del primer centenario del nacimiento de cine, reunió a cuarenta directores de todo el mundo que aceptaron la idea de hacer cada uno un cortometraje utilizando el aparato original inventado por los hermanos Lumière. Sin dudarlo, Bigas plantó a su maternal allattatrice sentada sobre un campo de cultivo recién arado mientras sostenía entre sus brazos a su hambriento pequeño. Rodado en un solo plano que dura algo menos de un minuto, la acción es mínima -a la mitad, la madre cambia al niño de su pecho derecho al izquierdo-, la composición está dominada por las líneas diagonales que marcan los profundos surcos en la tierra y la banda sonora está señoreada por el persistente canto de las cigarras. Se trata de una imagen poética muy hermosa, muy ajustada con lo que se conmemoraba, y en la que Bigas representa al cinematógrafo, "hijo de la máquina y del sentimiento", siendo recibido y alimentado por la humanidad sobre un terreno fértil y listo para florecer.

Después del escaso eco que obtuvo su película Son de mar, Bigas se refugió en un período que, acertadamente, Carolina Sanabria denomina "intrafílmico" (2009, p.81), en el que el artista se retira de modo momentáneo del mundo del cine para recuperar con fuerza en la creación gráfica, en el montaje teatral y la creación de video arte. Es justo en este último campo donde se reencontrará con sus queridas y despreocupadas lactantes. Como soporte audiovisual a la adaptación que de las Comedias Bárbaras de Valle Inclán llevó a cabo en 2003 , 
Luna rodó una serie de cortos en soporte digital. En uno de ellos, titulado El Mamador molar (2003) da una interesante vuelta de tuerca grotesca a la iconografía pues nos presenta a un viejo, calvo, feo y desdentado que ofrece sus servicios a las jóvenes lactantes para vaciar sus pechos cuando sus criaturas no querían mamar y estaban demasiados cargados de leche. "Resultado del contraste de estéticas -la vejez y la juventud, la fealdad y la hermosura- tan propio de Bigas, el corto rezuma cierto dejo grotesco que, a su vez, se refuerza con la toma donde, desde un primer plano, se muestra el cubo donde va a caer la leche que el viejo escupe y en el que flotan algunas moscas" (Sanabria, 2009, p.84). Este tema podría vincularse a cierta iconografía, de larga y rica tradición en la pintura cristiana occidental, basada en un cuento recogido por el escritor romano del siglo I Valerio Maximo en su libro Hechos y dichos memoriables. En él se cuenta cómo una joven romana llamada Pero amamantaba a escondidas a su anciano padre Cimón, encarcelado y sentenciado a muerte por inanición, hasta que el carcelero la descubrió y los jueces, conmovidos por este acto de caridad, decidieron liberar a su progenitor. De esta historia surge la célebre iconografía de la Caridad Romana. Junto con este también filmó Virgen Lactatio (2002) en la que presentaba la aparición de una virginal figura femenina que, toda vestida de blanco, se sienta sobre un enorme pedrusco plantado en medio de un sembrado. En su acogedor regazo duerme su hijo. Envuelta por el incesante canto de las cigarras, la mujer alza sus ojos desvelados por el potente sol del estío, para a continuación abrir su blusa con ternura y ofrecer su turgente seno al niño. La última de estas videocreaciones la intituló simplemente Allattatrice (2002). En esta ocasión la escena se desarrolla a orillas del Mediterráneo, un día luminoso y soleado. Entre las rocas dos jóvenes de rotundas siluetas se solazan con el ir y venir de las olas mientras tañen felices las campanas y disfrutan, como si de un singular duelo se tratara, tiroteándose con la leche que mana con fuerza inusitada de sus exuberantes senos ${ }^{12}$.

\footnotetext{
${ }^{12}$ Bigas concibió una versión masculina de estas mujeres maternales, los allattatores, una suerte de hombres amamantadores: "cuya primera mención fílmica había sido dada en la imaginación de Teté (cuyo padre "llenaba" de leche a la madre)-: una función que, en su mundo creacional, no es usual que la ejerza un varón. En 1995, la idea se concreta en un pequeño montaje en la Galería Sargentini de Roma, con la escenificación de un allattatore. Para este nuevo material, recupera a esta figura, con estética sombría, donde la figura masculina involuntariamente
} 
En Segundo origen (Segon origen, Carles Porta, 2015), un filme en el que Bigas estuvo trabajando hasta pocas semanas antes de morir, se cuenta una historia apocalíptica de corte ecologista. Alba y Dídac son los únicos supervivientes del holocausto que ha arrasado a los seres humanos de la faz de la Tierra. Sólo con el tiempo logran asumir su absoluta soledad y comienza a nacer entre ellos un vínculo poderoso. El amor no tarda en surgir y con los años Alba queda embarazada. Es entonces cuando el guion, en un claro guiño de homenaje a Bigas Luna, aprovecha para poner en escena y convertir a Alba en una nueva allattatrice. Bajo un enorme parasol y sobre la arena blanca descansa Alba amamantando a su hijo. Didac se acerca hasta ellos, lo observa con curiosidad, el bebé se separa del pecho y de su sabroso pezón brota un último suspiro de leche que el joven aprovecha para recoger un poco con su dedo y probarla. "Es amarga" comenta con una sonrisa y Alba le contesta: "Pero a él le gusta”.

Pero Bigas todavía tendría una última e inesperada oportunidad para mostrarnos una de estas mujeres nutricias. En el documental Bigas X Bigas presentado al final del verano del 2016 en el Festival de San Sebastián se recogía parte de las más de seiscientas horas del videodiario filmado, sin guion y sin ninguna planificación, por el director durante los últimos años de su vida. Bigas lo grababa todo y esta película compuesta por diversos cuadros donde se entremezclan escenas cotidianas, reflexiones, anécdotas suculentas, charlas cómplices con amigos y actores y momentos de intimidad, nos muestra al artista despojado de parafernalias, verdadero, auténtico. En uno de los momentos más entrañables del filme, Bigas irrumpe delicadamente en el cuarto de baño donde Aitana Sánchez Gijón, sonriente, desnuda y en la bañera, alimenta a su pequeño encarnando, sin esperarlo, una espontánea allattatrice. Como si de una estampa antigua se tratara, la cámara pudorosa filma el instante tiñendo la imagen de sepia. Hay silencio. Con un lento zoom el plano general se convierte en un primer plano mostrando como el pequeño se afana al pezón de su madre que lo observa complacida. Fuera de campo susurra Bigas Luna, quizás temeroso de romper la magia de aquel preciado momento: "Para él debe ser un éxtasis total. El agua, mamar...” ¿Se puede pedir algo más? 


\section{Conclusión}

A lo largo de su cinematografía, el cineasta catalán supo crear un complejo mapa iconográfico trufado de motivos visuales, personajes, temas y escenarios que, de un modo reiterado, entreveraron sus discursos fílmicos. De entre todo el repertorio de figuras retóricas que utilizó, una de las más persistentes y que además puede rastrearse prácticamente desde los prolegómenos de su carrera, es aquella que conjugaba con sutileza el erotismo con la gastronomía. Bigas comprendió que la relación entre el sexo y la comida era una cuestión cultural que identificaba la identidad de los pueblos como intentó demostrar, sobre todo y de un modo especial, en su trilogía ibérica.

\section{Referencias bibliográficas}

AAVV (1992). Bigas y Luna. Gijón: Festival Internacional de Gijón.

Alegre, L., Barreiro, J., Gistaín, M., Sánchez, A. \& Sánchez, B. (1999). Bigas Luna. La fiesta de las imágenes. Huesca: Festival de cine de Huesca.

Berthier, N., Larraz, E., Merlo, P. \& Seguin, J.C. (2001). Le cinema de Bigas Luna. Toulouse: Presses Universitaries du Mirail-Cinespaña.

Blaya, N. (2008). "IN=DENTRO. Los fluidos: Agua, leche, sangre". Ingestum, Valencia: Institut Valenciá d'art modern, Generalitat Valenciana. pp. 88-122.

Brillat-Savarin, J.A. (1978). Fisiología del gusto con una lectura de Roland Barthes, Madrid: Cupsa Editorial, Madrid.

Cavalieri, R. (2015). "Il gusto alimenta l'eros". Conjectura: Filosofía e Educaçio, Caixas do Sul, v. 20, ${ }^{\circ}$ 1, pp. 23-27.

Espelt, R. (1989). Mirada al mon de Bigas Luna. Laertes: Barcelona.

Fantoni Minnella, M. (200o). Bigas Luna. Roma: Gremese Editore.Martí Font, J.M. (1979). "Bigas Luna. El erotismo es una tontería". Star, $\mathrm{n}^{0}$ 51, octubre 1979, pp. 4-8.

Miñarro Albero, Lluis (1978). "Entrevista a Bigas Luna”. Dirigido por, ${ }^{0}{ }^{0} 8$, noviembre 1978, pp.17-20.

Morris, D. (2004). La mujer desnuda. Barcelona: Editorial Planeta.

Pisano, I. (2001). Bigas Luna. Sombras de Bigas, luces de Luna. Madrid: Sociedad General de Autores y Editores. 
Rodríguez González, Félix (2011). Diccionario del sexo y el erotismo. Madrid: Alianza Editorial.

Sanabria, C. (2009). "La otra producción visual de Bigas Luna”. Escena. Revista de las artes, 32(64), pp. 81-94. Sánchez, A. (1999). "El cine en el plato”. La fiesta de las imágenes, Huesca: Festival de cine de Huesca.

Sanabria, C. (2010). Bigas Luna. El ojo voraz, Barcelona: Laertes.

Weinrichter, A. (1992). La línea del vientre. El cine de Bigas Luna, Gijón: Ayuntamiento de Gijón. 